\title{
Cultural Heterogeneity in China and the Information Disclosure Quality of the Enterprises
}

\author{
Shu $\mathrm{Li}^{1{ }^{1 *}}$ Wei Wei ${ }^{1}$ Qing Jin ${ }^{1}$ \\ ${ }^{1}$ Accounting School, Shandong Youth University of Political Science, Jinan, Shandong, China \\ *Corresponding author.Email: lshu314159@163.com
}

\begin{abstract}
This paper studies the impact of cultural differences in different regions of China on the information disclosure quality of the enterprises. Using 5315 enterprises' annual data from different regions of China from 2016 to 2018, the researchers empirically tested the impact of different cultural dimensions on the information disclosure quality of the enterprises. The study found that uncertainty avoidance has a significant positive correlation with information disclosure quality of the enterprises, the future orientation has a significant negative correlation with the information disclosure quality of the enterprises, but other cultural dimensions are not significantly related to the information disclosure quality of the enterprises. Different from previous studies at the national level, this article provides new evidence from different regions within a country for the related research on "culture - accounting".
\end{abstract}

\section{Keywords: Chinese regional culture, cultural heterogeneity, information disclosure quality}

\section{INTRODUCTION}

High-quality information disclosure of the enterprises is critical to investors' decision-making. Therefore, a lot of research has focused on the factors that influence the information disclosure quality of the enterprises. Among them, as an informal system of social culture, its impact on the information disclosure quality of the enterprises has also attracted much attention. The existing literature on the influence of social culture on the information disclosure quality of the enterprises is mostly based on the Hofstede-Gray framework. On the basis of the Hofstede cultural dimension theory, Gray has established a framework that includes culture, accounting subcultures and accounting systems, and proposed social the specific path that social culture influences the accounting system. (Gray, 1988) A series of empirical tests were carried out on the basis of this framework, but the empirical tests did not reach a consistent conclusion. The reason for this inconsistency may be that the Hofstede-Gray framework is based on the national level. However, different countries may have different historical backgrounds, religious beliefs, and institutional environments. The above factors are usually difficult to measure accurately. They interact with cultural factors, and there are complex endogenous relationships among various variables. Even the accounting standards implemented by various countries

*Fund: 2020 Shandong Provincial Colleges and Universities "Young Innovation and Technology Plan" (2020RWG008); Shandong Youth University of Political Science Cultivation Project (XJPY2006). are different. Even if the standards are similar, the degree of compliance with the standards is very different. In this context, it is difficult to isolate the "net effect" of social culture on the information disclosure quality when testing the impact of national social culture on the information disclosure quality. In order to alleviate the above problems, some scholars deliberately selected countries in specific regions with similar historical backgrounds, religious beliefs, and institutional environments as their research samples when selecting samples. For example, Borker (2014) selected Egypt, Iran, and Iraq in the Middle East as the research samples for comparative analysis. Gray et al. (2015) selected developed economies in Europe as the research samples, and the higher degree of European integration can reduce the influence of other noncultural factors. However, to more accurately isolate the "net effect" of social culture, a better way is to limit the sample to one country and study the impact of cultural differences in different regions of the country on the information disclosure quality. A country that meets the above conditions should have two basic characteristics. One is that the regions of the country usually have similar historical backgrounds, common religious beliefs, the same application of laws and political and economic systems. Against this background, the impact of the above non-cultural macro-environmental factors can be minimized. Second, the choice of country requires a certain degree of heterogeneity in the culture of different regions of the country. China has a vast territory and multi-disciplinary theoretical analysis believes that "Chinese culture is multicultural". The analysis based on questionnaires by Zhao Xiangyang et 
al. (2015) also proved that Chinese culture has diverse characteristics. At the same time, the Chinese civilization has lasted for five thousand years. Since New China (1949), the people have shared a common sense of national and national identity. The attributes of an authoritarian state have made the whole China implement the same political and legal system. In summary, China can serve as one of the excellent samples for studying the above-mentioned issues. Based on this, the researchers used the GLOBE cultural and custom indexes of Chinese provinces surveyed by Zhao Xiangyang et al. (2015) as independent variables, and the information disclosure quality evaluation results of listed companies released by the Shenzhen Stock Exchange as the dependent variables, and empirically tested the influence of different cultural dimensions in various regions of China on the information disclosure quality of the enterprises. Research has found that uncertainty avoidance is significantly positively correlated with the information disclosure quality of the enterprises. Future orientation has a significant negative correlation with the information disclosure quality of the enterprises. However, other cultural dimensions have not been found to be significantly related to the information disclosure quality of the enterprises. The significance of this research is that compared with the empirical research at the national level, selecting different regions in the country as the research samples can minimize the impact of non-cultural macroenvironmental factors, which undoubtedly makes the empirical results more accurate and reliable. At the same time, the research enriches the influencing factors of the information disclosure quality of the enterprises and the related literature on "culture - accounting" research.

\section{LITERATURE REVIEW}

\section{A. The path of social and cultural influence on information disclosure: Hofstede-Gray framework}

Hofstede (1980) believed that culture is "a collective mental program that can distinguish different human groups." On the basis of this concept, Hofstede further divided culture into five dimensions, namely, uncertainty avoidance, power distance, masculinity (femininity), collectivism (individualism), and the future orientation added later. Gray (1988) established a framework that includes culture, accounting subculture and accounting practice on this basis. This framework provides two ways for social culture to influence accounting systems. The first is that social culture affects the accounting system by influencing institutional factors, namely: social culture institutional factors - accounting system; the second is that social culture affects accounting culture and then affects the accounting system, namely: social culture accounting culture - accounting system. Gray classified accounting culture into professionalism, consistency, conservatism and confidentiality, and predicted the relationship between various dimensions of Hofstede's social culture and accounting culture.

Gray divided the accounting system into four aspects: authority, execution, measurement and disclosure, and believed that the information disclosure is most relevant to confidentiality. In this way, Gray had established a link between social culture and the information disclosure of the enterprises. According to Gray's prediction, individualism and masculinity are negatively related to confidentiality, that is, positively related to higher levels of information disclosure, and uncertainty avoidance and power distance are positively related to confidentiality, that is, negatively related to higher levels of information disclosure.

Although there is still a system theory view, Nobes's (1998) country model and trust triangle theory can be used to explain the influence of social culture on the accounting system. However, because Gray's theory clearly puts forward the path that culture influences the accounting system, and hypothesizes the relationship between the social cultural dimension and accounting subculture, it is still the most important theoretical framework for analyzing cultural and accounting issues.

\section{B. Empirical test of the influence of social culture on information disclosure}

Gray and Vint (1995) selected the financial report disclosure quality index of 27 countries as the dependent variable to use Hofstede's socio-cultural dimension as an independent variable to test the impact of different countries' social culture on information disclosure. Uncertainty avoidance is positively related to confidentiality, and individualism is negatively related to confidentiality. The above conclusion supports Gray's prediction, but his research did not find a significant correlation between confidentiality and masculinity, and confidentiality and power distance. The research of Zarzeski (1996) added control variables based on Gray and Vint (1995), such as company size, debt ratio, and degree of multinational operations. He used data from 256 listed companies in 7 countries, and tested the impact of social and cultural dimensions on disclosure quality. The study found that individualism is positively correlated with the information disclosure quality, uncertainty avoidance is negatively correlated with the information disclosure quality, and masculinity is positively correlated with the information disclosure quality. However, at the same time, it is found that the relationship between power distance and the information disclosure quality is contrary to Gray's hypothesis. Wingate (1997) used the International Financial Reporting Index released by CIFAR as a dependent variable to test the impact of different social and cultural dimensions on the International Financial 
Reporting Index. His research found that individualism is positively related to the information disclosure quality, uncertainty avoidance is negatively related to the information disclosure quality, power distance is positively related to the information disclosure quality, and masculinity is negatively related to the information disclosure quality. Hope (2003) used a larger range of the samples to examine the relationship between various social and cultural dimensions and information disclosure. The study found that only individualism is positively correlated with the information disclosure quality, while other cultural dimensions are not significantly correlated with the information disclosure quality. Akman's (2011) sample data from six countries examined the relationship between social and cultural dimensions and information disclosure. The study found that power distance and uncertainty avoidance are negatively related to information disclosure, while individualism and masculinity are positively correlated with the amount of information disclosed. Vitolla et al. (2019) examined the relationship between various social and cultural dimensions and the quality of integrated financial reports. The study found that power distance, individualism, masculinity, and addiction are significantly negatively correlated with the quality of integrated financial reports, and uncertainty avoidance is significantly positively correlated with the quality of integrated financial reports.

In summary, existing studies have conducted empirical tests on the impact of social and cultural dimensions on the information disclosure quality based on cultural differences at the national level, but have not reached a consistent conclusion. The reason for this inconsistency may be that it is difficult for nationallevel research to separate the net effects of cultural factors from various other non-cultural factors.

\section{RESEARCH HYPOTHESIS}

Uncertainty avoidance refers to people against a specific cultural background trying to avoid the uncertainty of future events and reduce the degree of unpredictability of future events. Due to the existence of market supervision, providing low-quality information disclosure, or even illegal information disclosure, enterprises will have more uncertain consequences than providing high-quality information disclosure. Against the cultural background of high uncertainty avoidance, enterprises may be more inclined to provide high-quality information disclosure. Accordingly, hypothesis 1 has been proposed:

Hypothesis 1: Uncertainty avoidance is positively related to the information disclosure quality of the enterprises.

Power distance refers to the degree to which members of society recognize the unequal distribution of power against a specific cultural background. In the context of a high power distance culture, enterprise employees are more able to agree to unequal and even unreasonable power distribution within the enterprise. For example, it will be agreed that certain management personnel responsible for accounting will obtain the relevant authority of internal audit, which will go beyond the internal control of the enterprise and is not conducive to the provision of high-quality information disclosure by the enterprise. Accordingly, hypothesis 2 has been proposed:

Hypothesis 2: Power distance is negatively related to the information disclosure quality of the enterprises.

Performance orientation refers to the degree to which an organization or society encourages and rewards members to improve performance and perform well against a specific cultural background. In the context of high performance-oriented culture, enterprise management and employees are motivated by performance rewards and have the motivation to realize their short-term self-interests through manipulation of the information disclosure process, which will reduce the information disclosure quality of the enterprises. Accordingly, hypothesis 3 has been proposed:

Hypothesis 3: Performance orientation is negatively related to the information disclosure quality of the enterprises.

Social-oriented collectivism refers to the degree of collectivist behavior shown by members of society against a specific cultural background. Against the cultural background of highly socially oriented collectivism, all employees of the enterprise will show a higher concept of social collectives and emphasize the fulfillment of relevant social responsibilities to stakeholders, which will encourage the enterprise to provide higher-quality information disclosure to the outside world. Accordingly, hypothesis 4 has been proposed:

Hypothesis 4: Social-oriented collectivism is negatively related to the information disclosure quality of the enterprises.

The reliance of enforcement refers to the degree of decisiveness, dominance, and command of social members in their relationships with others against a specific cultural background. In the context of the culture the high reliance of enforcement, the management that decides the information disclosure of the enterprises may be more arbitrary, radical, and free from supervision and control. This will not help companies provide high-quality information disclosure to the outside world. Accordingly, hypothesis 5 has been proposed:

Hypothesis 5: The reliance of enforcement is negatively related to the information disclosure quality of the enterprises. 


\section{RESEARCH DESIGN}

\section{A. Samples}

The researchers selected A-share listed enterprises that were listed and traded on the Shenzhen Stock Exchange in China from 2016 to 2018 as the research samples. In order to reduce the impact of extreme values and special industries, the researchers further excluded ST(special traded), PT(particular transfer), financial industries and companies that first issued stocks that year. The researchers finally got 5315 annual-company samples. The relevant data comes from the website of the Shenzhen Stock Exchange of China and the CSMAR(China Stock Market \& Accounting Research) database.

\section{B. Variables}

1) Independent variable: Most of the empirical studies are based on the Hofstede-Gray framework, using the Hofstede socio-cultural dimension index, which is obtained by Hofstede through a questionnaire survey of IBM(International Business Machines) employees from different countries around the world. However, the above-mentioned cultural index has been widely criticized because of outdated data, unbalanced sample selection, IBM's exclusive organizational culture, and the rationality of cultural dimensions. (Baskerville, 2003, Orij, 2010) The cultural customs classification of GLOBE (2006) is a better choice for two reasons. First, it divides cultural customs into 9 dimensions, which include 5 cultural dimensions of Hofstede. Second, GLOBE's cultural customs emphasizes the characteristics of work and management, which are more suitable for research on "culture - accounting". Based on the purpose of studying Chinese regional culture, this article uses the score table of cultural characteristics of Chinese provinces released by Zhao Xiangyang et al. (2015) as a measure of cultural dimension. Zhao Xiangyang et al. (2015) used the method of distributing questionnaires to freshmen to form the GLOBE cultural customs index for each province. The index contains 9 dimensions, but Liu Wei and Huang Xiaoqi (2019) believed that there are two cultural dimensions that explain a cultural feature. 5 of the 9 cultural dimensions can be selected, namely uncertainty avoidance (UA), power distance (PD), performance orientation (PO), social-oriented collectivism (SC) and reliance of enforcement (RE).

2) Dependent variable: Since 2011, Shenzhen Stock Exchange of China has conducted regular evaluations on the information disclosure of listed enterprises every year. The assessment mainly focuses on the timeliness, accuracy, completeness, and legality of corporate information disclosure. At the same time, considering the rewards and punishments of listed companies and the cooperation with the Shenzhen Stock Exchange, the final assessment results of 4 levels of A, B, C, and D are comprehensively formed. A represents the highest quality of disclosure, and D represents the lowest quality of disclosure. This result represents the exchange's authoritative judgment on information disclosure quality of listed companies, and the evaluation results have been widely recognized by the media and public investors. This article uses the assignment method. When a listed company's specific annual assessment result is A, the company's information disclosure quality (DQ) for that year is assigned a value of $4, \mathrm{~B}$ is assigned a value of $3, \mathrm{C}$ is assigned a value of 2 , and D is assigned a value of 1 .

3) Control variable: In order to control the influence of other factors, the researchers selected several control variables at the macro level and the company level, including:

- Company scale (LNA), the natural logarithm of the total assets of the sample companies used at the end of the year.

- Financial leverage (LEV), the asset-liability ratio of the sample company at the end of the year.

- Profitability (ROE), the return on equity of the sample company.

- Growth ability (GROWTH), the operating income growth rate of the sample company.

- Shareholding ratio of the major shareholders (BSR), the shareholding ratio of the largest shareholder of the sample company.

- Consolidation of two positions (CON), if the chairman and general manager of the sample company are the same person, take 1 ; otherwise, take 0 .

- Audit opinion (OPINION), the sample company's audit report for the year is that the standard unqualified opinion takes 1 , otherwise it takes 0 .

- Accounting firm (AF), if the audit agency of the sample company in the current year is among the "big four" in the world, take 1; otherwise, take 0 .

- Ownership property (SOE), if the sample company is a state-owned enterprise, take 1; otherwise, take 0 .

- Economic development level (GDP), the natural logarithm of GDP per capita in the province where the sample company is located. 


\section{Model}

In order to test the above hypothesis, the following multiple linear regression model is set:

$$
D Q=\alpha_{0}+\alpha_{1} \times U A+\alpha_{2} \times P D+\alpha_{3} \times P O+\alpha_{4} \times S C+\alpha_{5} \times R E+\sum \text { Control }+\sum \text { Year }+\sum \text { Industry }+\varepsilon
$$

\section{EMPIRICAL RESULTS}

\section{A. Descriptive statistics}

From the following descriptive statistics in "Table I", the average value of the information disclosure quality score of the sample companies is 3.03 points, and the median value is 3 . The overall higher information disclosure quality may be related to China's stricter information supervision. In addition, the standard of each variable also shows good variability

TABLE I. DESCRIPTIVE STATISTICS

\begin{tabular}{lllllll}
\hline \multicolumn{1}{c}{ VarName } & \multicolumn{1}{c}{ Obs } & \multicolumn{1}{c}{ Mean } & \multicolumn{1}{c}{ MD } & \multicolumn{1}{c}{ Median } & Max \\
\hline DQ & 5315 & 3.03 & 0.641 & 1.000 & 3.00 & 4.00 \\
UA & 5315 & 4.37 & 0.095 & 4.150 & 4.37 & 4.56 \\
PD & 5315 & 4.62 & 0.179 & 4.340 & 4.56 & 4.91 \\
PO & 5315 & 4.65 & 0.101 & 4.420 & 4.66 & 4.91 \\
SC & 5315 & 4.69 & 0.088 & 4.410 & 4.72 & 4.87 \\
RE & 5315 & 4.15 & 0.098 & 3.900 & 4.15 & 4.41 \\
LNA & 5315 & 22.08 & 1.151 & 18.287 & 21.98 & 28.06 \\
LEV & 5315 & 0.39 & 0.204 & 0.017 & 0.38 & 3.17 \\
ROE & 5315 & 0.05 & 0.478 & -23.148 & 0.07 & 1.47 \\
GROWTH & 5315 & 0.38 & 2.714 & -0.982 & 0.16 & 87.48 \\
BSR & 5315 & 31.43 & 13.587 & 3.000 & 29.53 & 81.85 \\
CON & 5315 & 0.32 & 0.468 & 0.000 & 0.00 & 1.00 \\
OPINION & 5315 & 0.97 & 0.168 & 0.000 & 1.00 & 1.00 \\
AF & 5315 & 0.03 & 0.171 & 0.000 & 0.00 & 1.00 \\
SOE & 5315 & 0.23 & 0.419 & 0.000 & 0.00 & 1.00 \\
GDP & 5315 & 11.26 & 0.375 & 10.227 & 11.30 & 11.85 \\
\hline
\end{tabular}

\section{B. Regression analysis results}

According to the regression analysis results in the "Table II", it can be seen that the regression coefficient between uncertainty avoidance and the quality of corporate information disclosure is 0.34 , and it is significant at the $1 \%$ level, that is, uncertainty avoidance is significantly positively correlated with the quality of corporate information disclosure, which supports Hypothesis 1. At the same time, the regression coefficient between performance orientation and corporate information disclosure quality is -0.24 , and it is significant at the $1 \%$ level, that is, performance orientation and corporate information disclosure quality are significantly negatively correlated, which supports Hypothesis 3. However, no significant correlations were found between power distance, social-oriented collectivism and reliance of enforcement and the information disclosure quality of the enterprises. The empirical results did not provide evidence to support Hypothesis 2, Hypothesis 4, and Hypothesis 5.
TABLE II. REGRESSION RESULTS

\begin{tabular}{|c|c|}
\hline & $\begin{array}{l}\text { (1) } \\
\text { DQ }\end{array}$ \\
\hline UA & $\begin{array}{l}0.34 * * * \\
(2.99)\end{array}$ \\
\hline PD & $\begin{array}{l}-0.06 \\
(-1.05)\end{array}$ \\
\hline PO & $\begin{array}{l}-0.24 * * * \\
(-2.81)\end{array}$ \\
\hline SC & $\begin{array}{l}0.13 \\
(1.11)\end{array}$ \\
\hline RE & $\begin{array}{l}-0.07 \\
(-0.76)\end{array}$ \\
\hline LNA & $\begin{array}{l}0.13 * * * \\
(14.51)\end{array}$ \\
\hline LEV & $\begin{array}{l}-0.73 * * * \\
(-14.68)\end{array}$ \\
\hline ROE & $\begin{array}{l}0.07 \\
(1.20)\end{array}$ \\
\hline GROWTH & $\begin{array}{l}0.00 \\
(0.08)\end{array}$ \\
\hline BSR & $\begin{array}{l}0.00 * * * \\
(7.13)\end{array}$ \\
\hline $\mathrm{CON}$ & $\begin{array}{l}-0.01 \\
(-0.49)\end{array}$ \\
\hline OPINION & $\begin{array}{l}1.03 * * * \\
(16.50)\end{array}$ \\
\hline $\mathrm{AF}$ & $\begin{array}{l}0.11 * * \\
(2.54)\end{array}$ \\
\hline SOE & $\begin{array}{l}0.11^{* * * *} \\
(5.42)\end{array}$ \\
\hline GDP & $\begin{array}{l}0.04 \\
(1.18)\end{array}$ \\
\hline _cons & $\begin{array}{l}-1.49^{*} \\
(-1.86)\end{array}$ \\
\hline $\begin{array}{l}\mathrm{R}^{2} \\
\text { Adjust- } \mathrm{R}^{2} \\
\mathrm{~N}\end{array}$ & $\begin{array}{l}0.206 \\
0.20 \\
5315\end{array}$ \\
\hline
\end{tabular}




\section{CONCLUSION}

This paper examined the impact of cultural differences in different regions of China on the information disclosure quality of the enterprises. Using the evaluation results of the information disclosure work of listed companies released by the China Shenzhen Stock Exchange as the dependent variable, and using the cultural characteristics of China's provinces released by Zhao Xiangyang et al. (2015), this paper tested the impact of various cultural dimensions on the information disclosure quality of the enterprises by establishing multiple linear regression model. Researchers have found that uncertainty avoidance is significantly positively correlated with the information disclosure quality of the enterprises. This conclusion is contrary to Gray's prediction. This may be due to China's high-strength supervision of listed companies, which makes the cost of corporate violations higher, that is, providing illegal information disclosure will have more uncertain consequences than providing high-quality information disclosure. The study also found that performance orientation is negatively correlated with the information disclosure quality of the enterprises. This may be because, in the context of high performance orientation, corporate management and employees are motivated by performance rewards and are motivated to reduce the disclosure quality due to self-interested behavior. However, the study did not find a significant correlation between power distance, social-oriented collectivism and reliance of enforcement and the information disclosure quality of the enterprises. Different from previous empirical studies at the national level, selecting a different region in the country as the research sample can minimize the impact of noncultural macro-environmental factors and improve the reliability of the empirical results.

The practical enlightenment of this article is that since a specific regional culture can significantly affect the information disclosure quality of the enterprises, targeted cultivation or suppression of the corresponding cultural atmosphere in the industry can significantly improve the overall information disclosure quality of the enterprises.

\section{References}

[1] Akman,N.H. 2011."The Effect of IFRS Adoption on Financial Disclosure: Does Culture Still Play A Role?". American International Journal of Contemporary Research. Vol.1 No.1,pp.6-17.

[2] Baskerville R.F. 2003, Hofstede Never Studied Culture. Accounting, Organizations and Society. Vol 28:1-14.

[3] Borker, D. R. "IFRS and Socio-Cultural Orientation In Egypt, Iran And Iraq". Journal of Accounting \& Finance (2158-3625); 2014, Vol. 14 Issue 5, pp.175-185.
[4] Gray, S. and Vint, H. 1995, "The Impact of Culture on Accounting Disclosures: Some International Evidence", AsiaPacific Journal of Accounting, Vol. 2 No. 1, pp. 33-43.

[5] Gray, S. J. 1988, "Towards a theory of cultural influences on the development of accounting systems internationally", Abacus, Vol. 24, pp. 1-15.

[6] Gray, S.J., Kang, T., Lin, Z. and Tang, Q. 2015, "Earnings Management in Europe Post IFRS: Do Cultural Influences Persist?", Management International Review, Vol. 55 No. 3, pp. 827-856.

[7] Hofstede, G. 1980, "Culture's Consequences — International Differences in Work-related Values", Beverly Hills, London: Sage Publications.

[8] Hope, O.K. 2003, Firm-level Disclosures and the Relative Roles of Culture and Legal Origin. Journal of International Financial Management \& Accounting. Vol. 14: 218-248.

[9] Liu Wei. Huang Xiaoqi.2019. "Economic Policy Uncertainty,Regional Culture, and Insurance Demand”. Journal of Financial Research. Vol.471 No.9, pp.39-56. (in Chinese)

[10] Nobes.C.1998. Towards a General Model of the Reasons for International Differences in Financial Reporting. Abacus. Vol. 34,pp.162-187.

[11] Orij, R. 2010, "Corporate Social Disclosures in the Context of National Cultures and Stakeholder Theory", Accounting, Auditing \& Accountability Journal, Vol. 23 No. 7, pp. 868 -889.

[12] Vitolla, F., Raimo, N., Rubino, M., \& Garzoni, A. (2019). The Impact of National Culture on Integrated Reporting Quality. A Stakeholder Theory Approach. Business Strategy and the Environment, 28.

[13] Wingate, M. L.1997. An Examination of Cultural Influence on Audit Environments. Research in Accounting Regulation. Vol. 11, pp. 129-148.

[14] Zarzeski, M.T.1996. Spontaneous Harmonization Effects of Culture and Market Forces on Accounting Disclosure Practices. Accounting Horizons. Vol. 10: 18-37.

[15] Zhao Xiangyang, Li Hai and Sun Chuan. "The Regional Cultural Map in China: Is It 'the Great Unification' or 'the Diversification'?", Management World, Vol. 2, pp. 101-119. (in Chinese) 